\title{
TREE-RING STUDIES ON AGATHIS AUSTRALIS (KAURI): A SYNTHESIS OF DEVELOPMENT WORK ON LATE HOLOCENE CHRONOLOGIES
}

\author{
ANTHONY FOWLER*, GRETEL BOSWIJK, and JOHN OGDEN \\ School of Geography and Environmental Science \\ The University of Auckland \\ Private Bag 92019 \\ Auckland, New Zealand
}

\begin{abstract}
The potential of kauri (Agathis australis) for paleoclimate research is well established. Multiple treering chronologies have been derived from living and sub-fossil material and growth-climate relationships have been identified. Work has progressed to the stage where raw ring-width data and chronologies covering the last half of the second millennium can confidently be placed in the public domain, to facilitate multiproxy paleoclimate studies. This paper outlines progress in deriving kauri tree-ring chronologies, summarises data availability and quality, and explores the scope for developing composite chronologies. Statistical quality control of the available data was undertaken, following application of an "optimum" standardisation technique. Variations in sample depth with time and between sites result in a complex evolving pattern of chronology quality across sites. Analysis of inter-site statistical relationships identified a pervasive regionalscale signal in kauri with some minor secondary patterns. In light of the strong common signal, a kauri master chronology was built by pooling tree-ring series. Analysis of the quality of this chronology indicates that high-quality master chronologies can be derived for A.D. 1597-1996 from as few as 25 trees from seven sites.
\end{abstract}

Keywords: tree rings, kauri, Agathis australis, New Zealand.

\section{INTRODUCTION}

Agathis australis (kauri) is a New Zealand canopy emergent noted for its longevity and size. Mature adults can reach $30 \mathrm{~m}$, with trunks often greater than $2 \mathrm{~m}$ in diameter. Trees frequently live for $600+$ years and ages in excess of 1,000 years are known (Ahmed and Ogden 1987). Kauri is the only member of the genus Agathis (Araucariacae) occurring naturally in New Zealand, where its distribution is restricted to north of latitude $38^{\circ} \mathrm{S}$ (Figure 1). It is found predominantly in lowland forests, but also grows at altitudes greater than 500 $m$ in the east of the upper North Island. Ridge tops are the most favored growth locations, although there are numerous examples of trees growing in other situations, including adjacent to streams and estuaries.

The prospects of kauri for tree-ring studies have been recognised for several decades (Bell and

*Corresponding author: a.fowler@auckland.ac.nz.
Bell 1958; Ogden 1978; La Marche et al. 1979). The longevity of the species makes it an obvious candidate, particularly in view of the abundance of living trees in relatively undisturbed environments, and despite widespread logging in the late 19th and early 20th Centuries. Paradoxically, past logging has created additional tree-ring research opportunities because substantial relic material is held in museums or remains as abandoned stumps. This wood often covers the first half of the second millennium, a very difficult period to sample using non-destructive coring because of kauri's large size (cores from fully mature trees rarely get close to the pith). There is also a substantial resource of sub-fossil kauri wood, preserved in swamps. Recent work on sub-fossil material (Boswijk et al. 2001; Fowler et al. 2001) suggests that a continuous record extending back at least 4000 years is possible. In addition, ancient kauri, radiocarbon dated to $20,000-40,000+$ years B.P., has been recovered from swamps. 


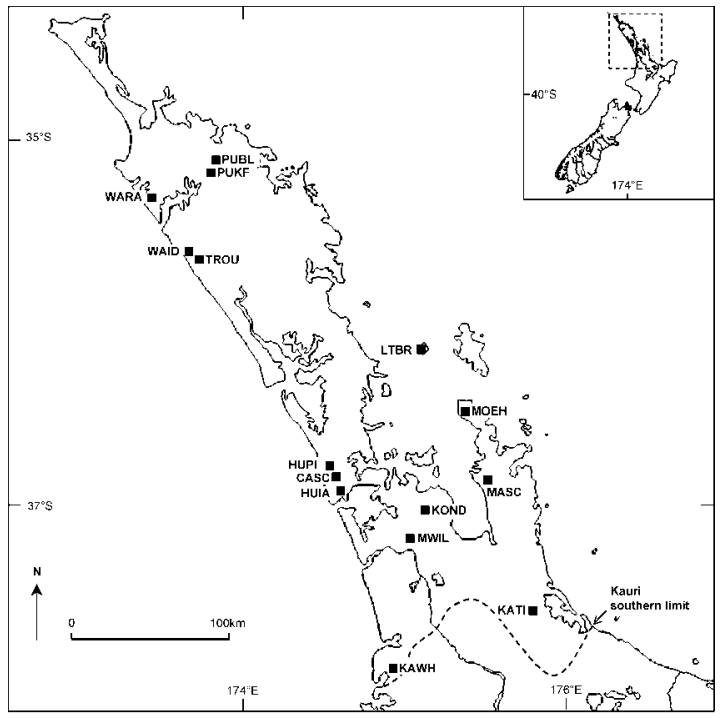

Figure 1. Locations of 15 modern kauri chronology sites.

Buckley et al. (2000) summarized tree-ring research on modern kauri (living and standing dead trees) up to 1998. Subsequent work has added new sites (including some sites where crossdating had previously failed) and extended some site chronologies back in time. Rigorous quality control has been applied to all existing material and detailed analyses of inter-site relationships have been undertaken, the latter focused on ascertaining the potential for building master chronologies. This paper synthesizes modern kauri treering research to 2002 , as a prelude to climate reconstruction.

\section{THE MODERN KAURI DATA BASE}

The first known tree-ring research on kauri was undertaken by Bell and Bell (1958). They successfully crossdated "several specimens" from Cascades Kauri Park and suggested that chronology construction "may be possible". A subsequent attempt at chronology development by Dunwiddie (1979) also achieved limited success. Although trees from three sites were sampled, only a single site chronology from Konini Forks (KOND) was developed (La Marche et al. 1979). Dunwiddie (1979) observed that kauri has notable growth anomalies, which can affect crossdating between trees from the same site. These include locally absent rings and/or false rings, as well as a tendency to poor circuit uniformity, and wedging and compression of rings. However, such problems can usually be resolved by analysis of multiple samples from each tree and rigorous crossdating within and between trees.

Eleven new kauri site chronologies distributed across the range of kauri growth were established in the 1980s (Palmer 1983; Fowler 1984; Ahmed and Ogden 1985; Figure 1). Collectively these spanned A.D. 1580-1981. Sites were predominantly in mature undisturbed forest covering an area of at least two hectares, with no obvious signs of recent disturbance, and with trees greater than 0.6-m diameter at breast height present. Crossdating was most successful from north-facing sites. It was anticipated that kauri growing on northern slopes would experience greater extremes of temperature and soil moisture, and therefore be sensitive to climate (Ahmed and Ogden 1985).

Buckley et al. (2000) updated KATI to 1997 (10 new trees) and built the first kauri master chronology (A.D. 1580-1997) from series from eight sites (Table 1). MOEH was excluded as it correlated poorly against the other sites. CASC and HUIA were not used because of lost data. Buckley et al. applied a relatively conservative standardisation technique to individual series, designed to minimise loss of climate information.

The Buckley et al. (2000) synthesis was noteworthy in applying consistent chronology construction techniques across all sites and in developing knowledge of the relationship between climate and kauri, but made little contribution to the expansion of the database. Since then the network of kauri chronologies has been spatially and temporally increased with the addition of several new or reconstructed chronologies and the revision of one site (MOEH) (Table 1). The modern kauri database now includes 15 crossdated site chronologies distributed throughout the geographical range of kauri. Chronological coverage now extends back to A.D. 1269, although sample depth is low for several centuries (Figure 2). In addition, recent analysis of a large display section, of unknown origin, produced a single series (1 tree/6 radii; 690 years) with a pith date of A.D. 911 that crossdates 
with older sections of MOEH, MASC, and HUPI. The increased record length resulting from recent work provides the foundation for the development of a long kauri chronology linking modern, archival, and sub-fossil material.

\section{QUALITY CONTROL AND ASSESSMENT}

\section{Maximising the Common Signal}

Kauri grow in closed canopy forests and are subject to competitive pressures throughout their lives. They are prone to wind damage (often losing major branches) and frequently exhibit growthform anomalies. These competitive/injury/growth characteristics have clear expression in ring-width time series, such as those presented in Figures 3A-D for a tree from the CASC site. Decline in ring widths with age is typical but century-scale periods of growth suppression or release can occur at any time, probably related to evolving competitive pressures. Decadal-scale variation is normally superimposed on the century-scale trends, CASC002d being a clear example of this (Figure 3D). Decadal-scale departures are usually radiispecific, indicative of competition, injury, or growth idiosyncrasies rather than variable climate forcing. The climate signal is primarily expressed in high-frequency year-on-year variations.

The implications of standardising tree-ring series using smoothing splines of differing stiffness are demonstrated in Figure 3. The three smooth curves plotted through the four ring-width time series in Figure 3 (dashed lines, Panels A-D) are splines of differing stiffness. Spline10 fits the time series closely, following all inter-decadal variation in the data and some intra-decadal variation (e.g. the late 1910s sequence of wide rings in Panel D). Spline20 is more "conservative", not following peaks and troughs as closely and largely unaffected by intra-decadal variation. Spline50 is the stiffest, following underlying century-scale trends in the data, although some influence of multi-decade departures is apparent in all four time series.

Figure $3 \mathrm{~F}$ shows intra-tree correlations for each spline with a 31-year moving window. The general pattern of increased correlation amongst series with increased spline flexibility is consistent with the contention that decadal-scale variance removed using flexible splines is mostly endogenous noise. In terms of enhancing the common (highfrequency) signal, the implication is that tight curve-fitting options are most appropriate for kauri. Note that tree-ring indices have been calculated by the commonly used ratioing method.

The generality of the results presented in Figure 3 for one tree was tested across all 15 crossdated sites in Table 1 by running multiple standardisation runs for each site with different spline stiffness settings. The effectiveness of different splines at removing endogenous noise was assessed using the mean correlation between all indexed series at the site. A trend to higher mean intra-site correlations with increased spline flexibility is apparent across all 15 sites (Figure 4). The trend is consistent across all sites from the stiffest splines applied (50\% variance cut-off at 100 years) through to relatively flexible splines with $50 \%$ variance cut-off at 20 years (Spline20 in Figure 3). More flexible splines, up to the limit of $50 \%$ variance cut-off at 10 years (Spline10 in Figure 3), further increased mean intra-site correlation at most sites but had the reverse effect for some sites.

For subsequent analysis, all sites were standardised using a spline with $50 \%$ variance cut-off at 20 years. A consistent approach across sites was thought appropriate to facilitate inter-site comparisons, although we acknowledge that alternative approaches (such as interactive fitting of standardisation curves) may also be appropriate. The relatively flexible curve-fitting approach was used to maximise the common signal. Even more flexible splines were considered inappropriate because of relatively small additional improvements in intrasite correlations and poorer intra-site correlations for some sites. Note that the flexible standardisation splines used here eliminate most multi-decadal scale variance. The derived tree-ring chronologies are ideal for crossdating purposes and have utility for investigating high-frequency climate forcing, but re-standardisation using less flexible curves would be required for studies of multi-decadal forcing.

\section{Statistical Quality of the Site Chronologies}

Replication is a key signal-enhancement component of tree-ring chronology development. In- 
FOWLER, BOSWIJK, and OGDEN

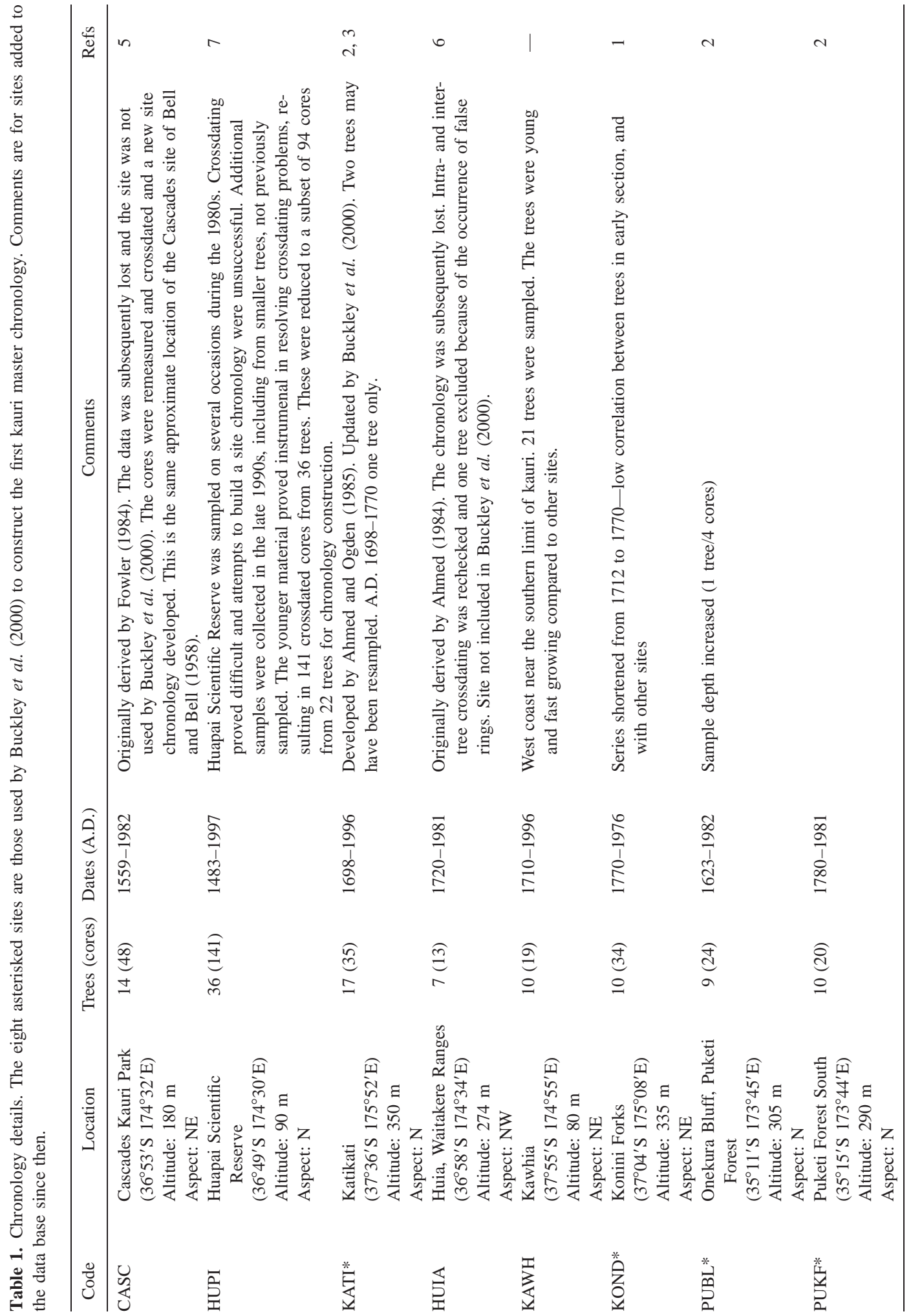




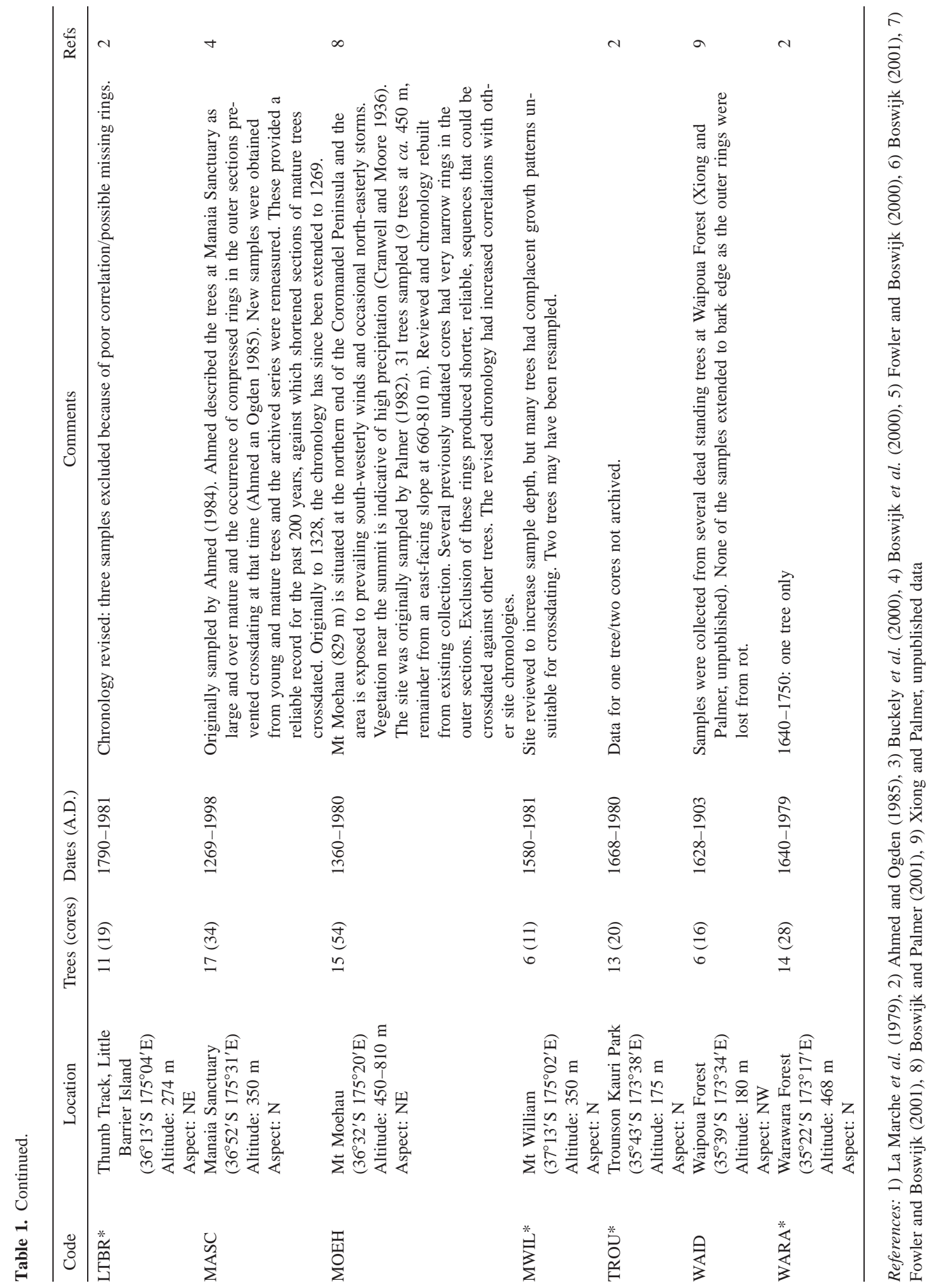




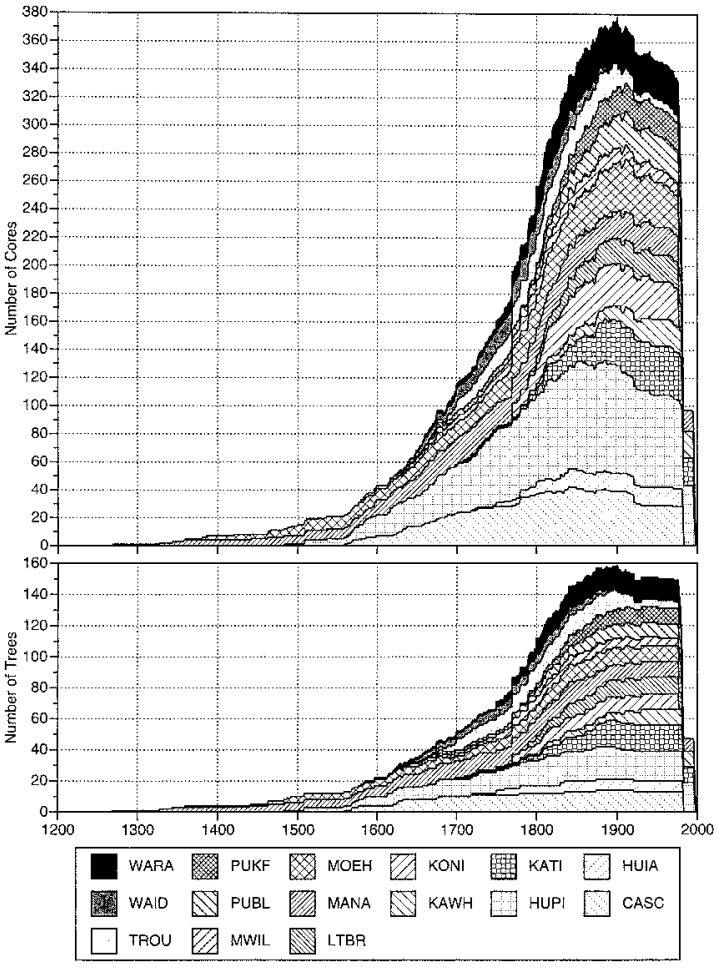

Figure 2. Sample depth across the 15 modern kauri chronology sites.

creased sample size is generally beneficial and the natural inclination is to include all the crossdated material in construction of a site chronology. However, although maximising sample size is generally advantageous, situations may arise where the inclusion of some samples is detrimental to the quality of a site chronology. Possible reasons for aberrant samples include crossdating errors, uncharacteristic growth response to environmental forcing by one or a group of individuals (possibly from local variations in site characteristics), and systematic variations in growth response associated with age/size. Fowler and Boswijk (2001) identified a clear example of a size-dependent relationship in kauri (Figure 5).

In view of the above, a quality control procedure was initiated across all sites to test the merits of including each crossdated series in the construction of the site chronologies. Chronology quality was assessed using the Expressed Population Signal (EPS) statistic (Briffa and Jones 1990). The "chronology stripping" procedure involved removing series, which lowered chronology EPS. Details of the methodology and results are given in Fowler and Boswijk (in press). Series were removed from 11 of the 15 sites for relatively modest EPS improvements, roughly equivalent to including one more tree in the chronology (Fowler and Boswijk 2003).

The relationship between the number of trees and EPS of the stripped chronologies (Figure 6A) indicates the kauri sample size required to be confident of attaining an arbitrary EPS threshold. Scatter about the regression line in Figure 6A relates to the strength of the common signal between trees. This is the explanation for the relatively poor EPS statistics for WAID and KAWH. We conclude from this that 10 trees is a reasonable minimum target for site chronology depth, although it should be noted that this result is sensitive to the flexibility of the standardisation splines used. More trees would be needed to achieve the same EPS threshold when more conservative standardisation is used (17 trees for standardisation using 200-year splines-Fowler and Boswijk 2003).

The statistical quality of a tree-ring chronology will usually vary through time with changes in sample size (Figure 2). In this context, the overall chronology EPS statistic is an incomplete measure of quality because it will normally represent only the most recent period, when sample depth is greatest. This is confirmed by analysis of EPS through time for each site (Figure 6B). For example, although EPS $\geq 0.95$ is reported for two sites (HUPI, KATI, Figure 6A), that standard was only attained for 131 and 94 years, respectively. Similarly, although EPS $\geq 0.80$ is reported for WAID, it is sustained for only 11 years. MWIL is somewhat unusual in that EPS is $\geq 0.90$ for A.D. 1670-1739 when overall EPS is only 0.854 .

For the purpose of subsequent inter-site comparisons, two time periods were selected where the statistical quality of the data across selected sites was considered optimal. Figure $6 \mathrm{~B}$ was the basis for time period selection. It is apparent from this figure that the quality of two sites (KAWH, WAID) is noticeably inferior to the other 13 . They were discarded as unsuitable for inter-site analyses. For the remaining 13 sites, the two selected high-quality periods are: 

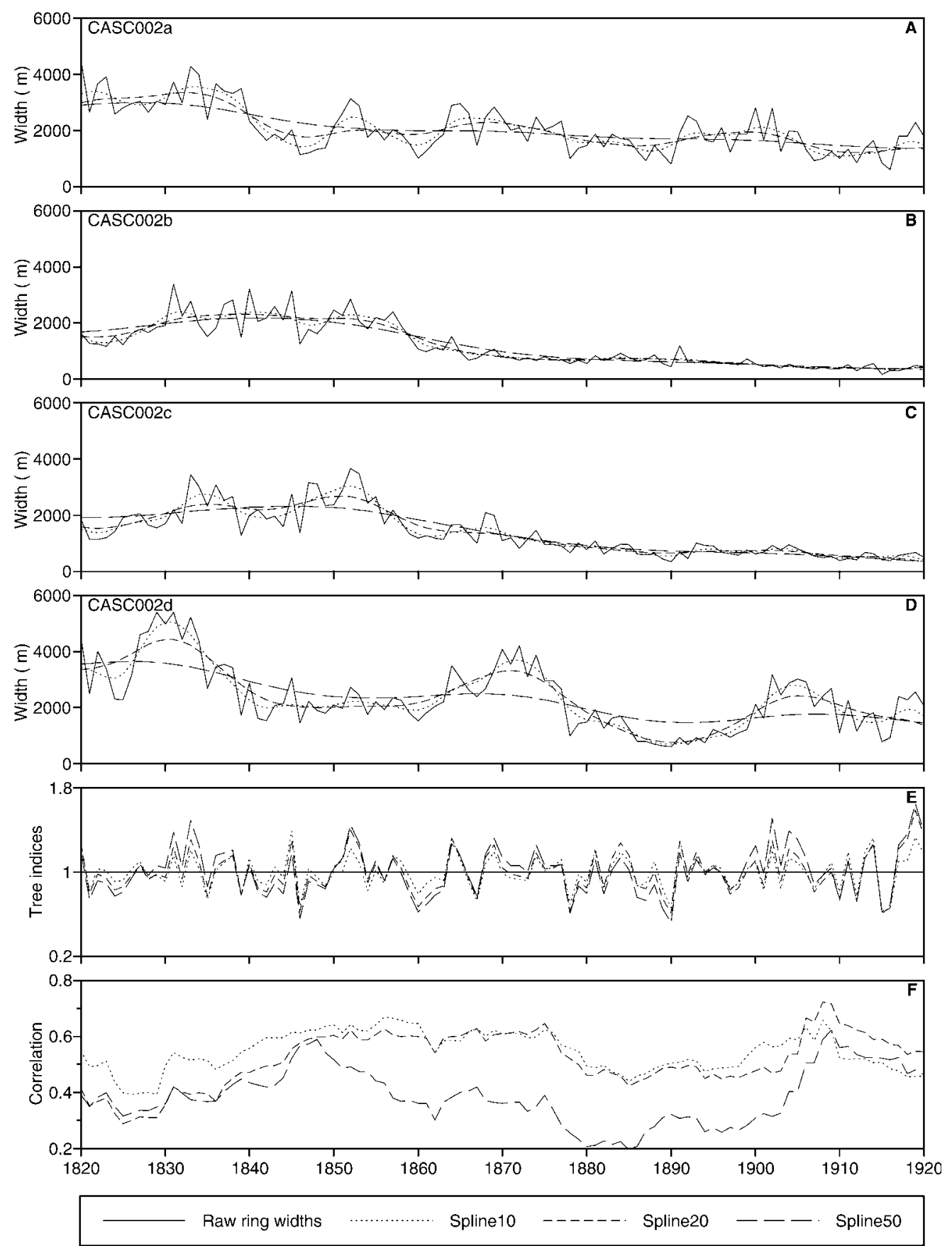

Figure 3. Examples of fitting splines of different stiffness for standardisation of tree-ring time series. Panels A-D are four series from the same tree, each with three splines fitted. The number in each spline label $(10,20,50)$ is the $50 \%$ variance cutoff defining spline stiffness (see text and Figure 4 for details). Panel E shows indices for the tree when the four detrended indices are averaged, for each spline option. Panel F shows the mean intra-tree correlation for each spline for a 31-year moving window centred on the plotted value. The ARSTAN program developed by Cook (Cook 1985; Holmes et al. 1986) was used here for standardisation. 


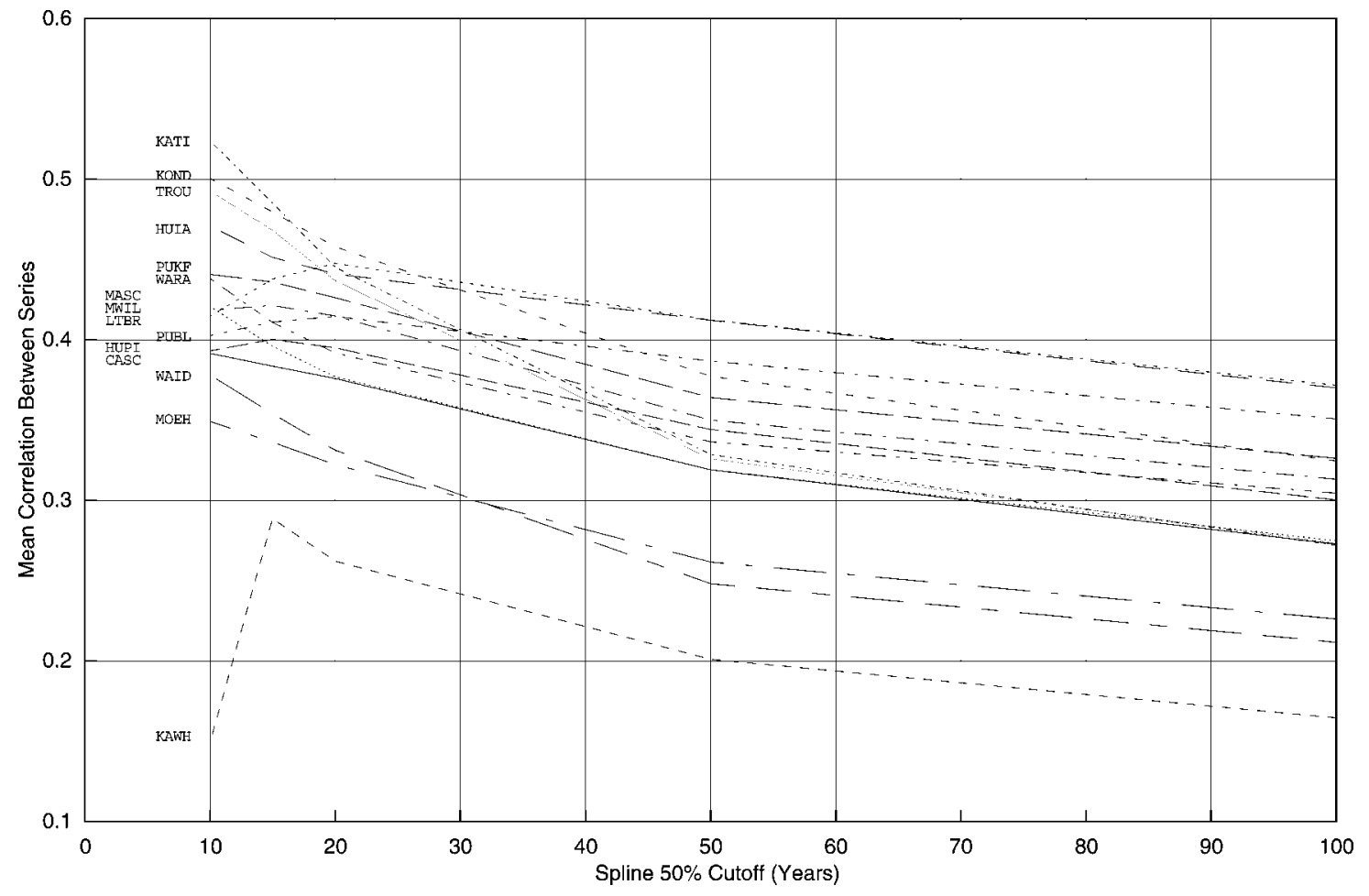

Figure 4. Mean intra-site correlation as a function of standardisation spline $50 \%$ variance cutoff.

1) A.D. $1823-1976 \mathrm{EPS} \geq 0.80$ at all 13 sites, except TROU (truncated at 1920)

2) A.D. $1840-1920$ EPS $\geq 0.85$ at all 13 sites

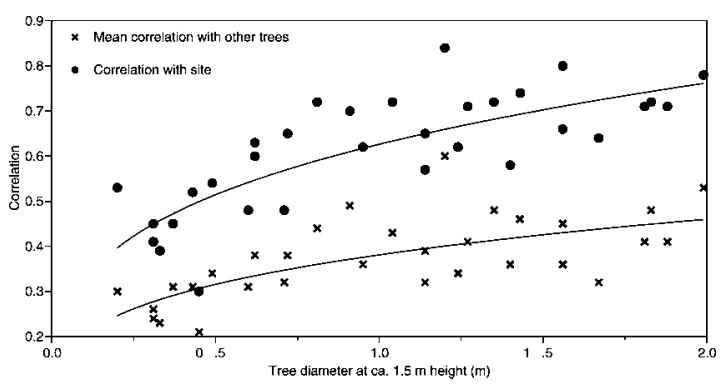

Figure 5. Mean inter-tree correlation and correlation of trees with a composite site chronology at HUPI, showing dependence on tree size. $\mathrm{X}$-symbols show the mean correlation of each tree (plotted by DBH) with 31 other trees. Filled circles show the correlation of the tree with a site index averaged across 36 crossdated trees (DBH unavailable for four trees). Regression lines are of power form. The much higher correlations against the site chronology demonstrate the signal enhancement effect of replication and averaging. Source: Fowler and Boswijk (2001).

\section{POTENTIAL FOR BUILDING KAURI MASTER CHRONOLOGIES}

Frequency analysis by year of the distribution of indices across 13 sites (Figure 7) reveals a strong regional-scale signal in the kauri site chronologies. All site indices have the same sign in $18 \%$ of years and $77 \%$ of sites (10 of 13) have the same sign in $60 \%$ of years. As the agreement in sign between sites rises so too does the mean departure of the indices away from one, suggesting that the widest and narrowest rings are associated with a regionally pervasive influence. Very narrow or wide rings sometimes occur only at one or a few sites (e.g. A.D. 1908, 1917), although even here a clear majority of sites deviate from normal in the same direction. Where several sites exhibit a strong common direction of change, it is unusual to find other sites showing an opposite response pattern and very rare for it to be significant. A strong common deviation from normal occurs in some years (e.g. A.D. 1839, 1963). It is also noteworthy that the response pattern for narrow and 

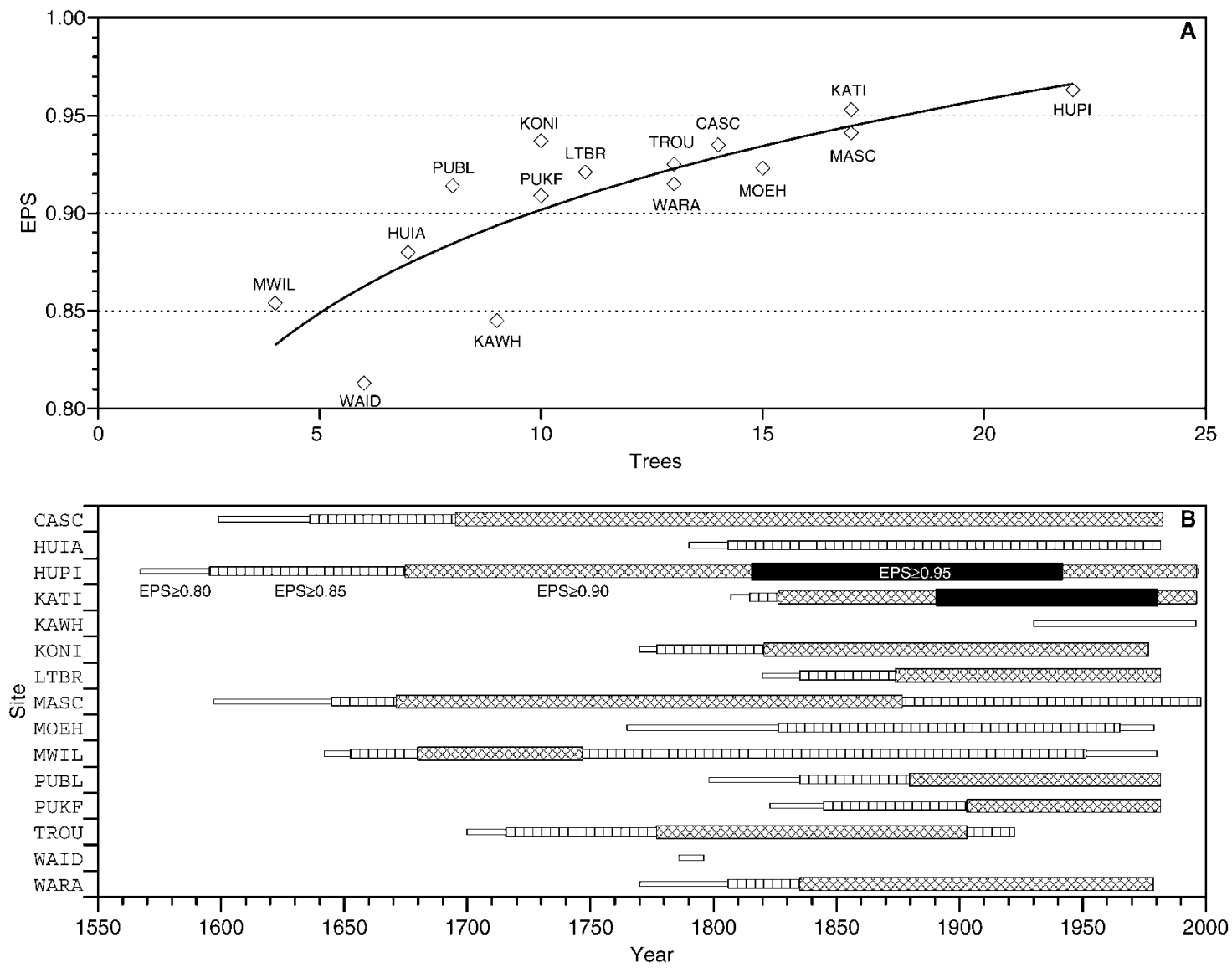

Figure 6. Statistical quality of 15 modern kauri sites, as represented by the EPS statistic. Site codes from Table 1 . The key to shading in Panel B is as shown for HUPI.

wide rings is very similar. For example, the $18 \%$ of years in which all sites have a common direction of response are equally split between wide and narrow rings.
Principal components analysis (SAS, 1990) of the 1840-1920 data set was run to assess the statistical strength of the common signal across sites. The analysis was run on the correlation rath-

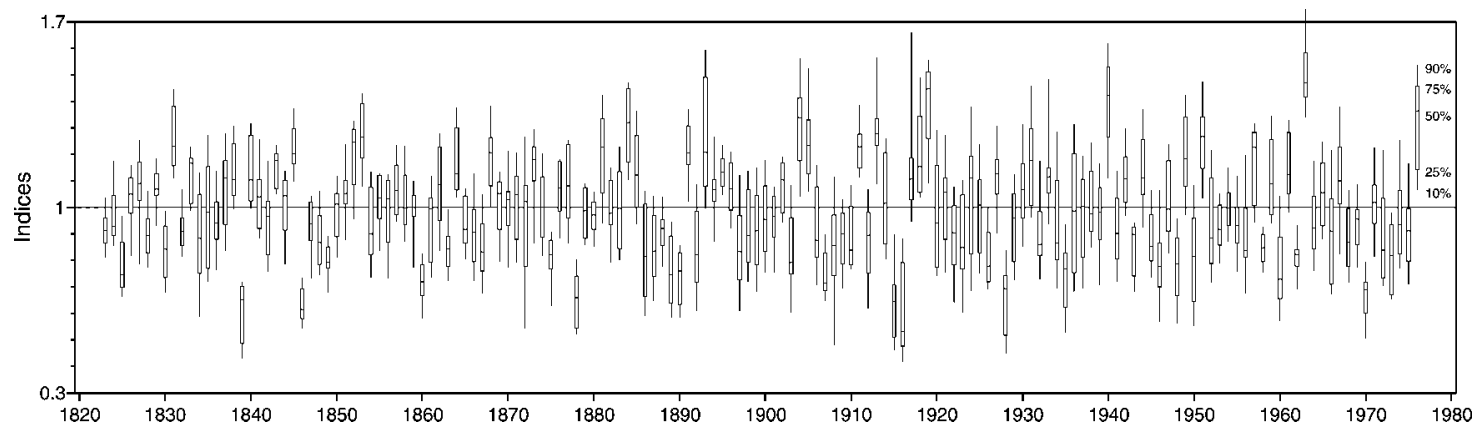

Figure 7. "Box and whiskers" plot representation of tree-ring indices across 13 sites (KAWH and WAID excluded), showing 10th, 25th, 50th, 75th, and 90th percentiles. 


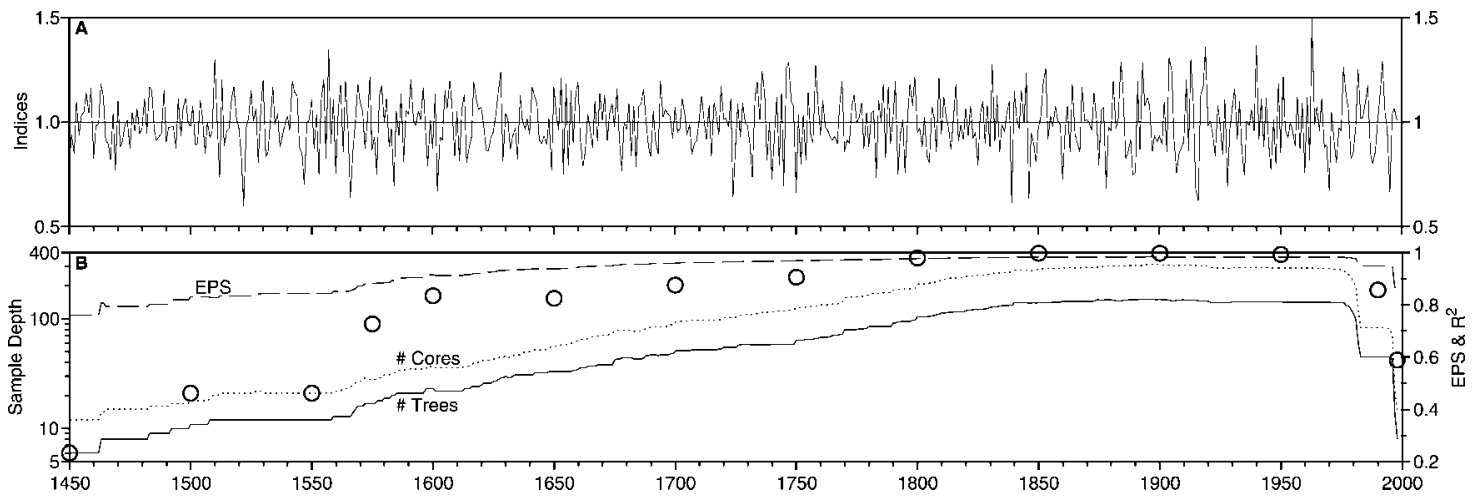

Figure 8. Kauri master chronology (A.D. 1450-1998). $r^{2}$ values in Panel B (circles) are calculated over A.D. 1840-1920 between the kauri master (Panel A) and sub-chronologies constructed using only those series available at the selected time periods shown.

er than covariance matrix because the 13 sites have unstandardised variance. The key result of the analysis is the dominance of the first principal component (PC1). PC1 explains 59\% of the variance in the data, all sites weight positively on it within a narrow range $(0.24-0.31)$, and there are no outliers. We deduced from this that PC1 represents a strong common signal across all kauri sites, validating our contention that there is a strong regional-scale signal in the chronologies. Construction of a master chronology by pooling data from across the geographical range of kauri was therefore considered appropriate.

The kauri master tree-ring chronology was constructed by treating all trees as samples from a common site (kauri's complete geographic range). Standardised series were combined into tree means that were then averaged to produce the master (Figure 8A). This resulted in a time series of unequal sample depth through time (Figure 8B), but one where the implications of changing sample depth could be assessed. The approach was considered preferable to deriving the master by combining site chronologies, where inter-site differences in quality (evolving through time in a complex manner) would have made it difficult to assess the evolving quality of the master. A tree-based approach had the added advantage of permitting incorporation of additional material. This included trees from KAWH and WAID, where sample depth was insufficient to develop high-quality site chronologies, and a further tree (DISP) of unknown provenance, but thought to have been a logging relic dating to the beginning of the 20th Century. Series removed as part of the site-by-site quality control were not included in the building of the master chronology.

The kauri master ostensibly extends from A.D. 911-1998, but has such low sample depth for the first several centuries (one tree until A.D. $1269,5+$ only from A.D. 1360) that it probably has limited value before about A.D. 1600, at least in the context of climate reconstruction. Trees from six sites contribute to the master by A.D. 1600, climbing to 10 by A.D. 1700 . Sample depth peaks at 315 radii (151 trees, 15 sites) by A.D. 1900 and is close to this level from the mid 19th Century to the late 20th Century.

The composition of the kauri master evolves in a complex manner through time as trees and entire sites are included or drop out of the index calculation. For the period A.D. 1800-1980, the master is built from at least 104 trees from a minimum of 13 sites, and is probably little affected by bias associated with changes in composition. However, before A.D. 1800 and after A.D. 1980, sample depth is markedly lower and the master is built from rapidly evolving subsets of trees and sites. Although we have identified a common growth response across the geographical range of kauri, the master derived for each subset will likely be biased.

By way of example, consider the year A.D. 1550. For this year the kauri master is built from 12 trees from four sites (HUPI, MASC, MOEH, DISP). EPS is relatively high at 0.845 (Figure $8 B$ ), 
Table 2. Inter-site correlation coefficients for 13 sites.

\begin{tabular}{|c|c|c|c|c|c|c|c|c|c|c|c|c|c|}
\hline & CASC & HUIA & HUPI & KATI & KOND & LTBR & MASC & MOEH & MWIL & PUBL & PUKF & TROU & WARA \\
\hline CASC & - & 0.66 & 0.65 & 0.49 & 0.51 & 0.68 & 0.57 & 0.35 & 0.70 & 0.49 & 0.63 & 0.57 & 0.38 \\
\hline HUIA & - & - & 0.69 & 0.51 & 0.57 & 0.66 & 0.58 & 0.63 & 0.70 & 0.50 & 0.59 & 0.59 & 0.62 \\
\hline HUPI & - & - & - & 0.40 & 0.59 & 0.69 & 0.47 & 0.54 & 0.70 & 0.38 & 0.52 & 0.61 & 0.37 \\
\hline KATI & - & - & - & - & 0.65 & 0.43 & 0.57 & 0.40 & 0.52 & 0.62 & 0.64 & 0.28 & 0.51 \\
\hline KOND & - & - & - & - & - & 0.59 & 0.59 & 0.44 & 0.65 & 0.55 & 0.66 & 0.40 & 0.45 \\
\hline LTBR & - & - & - & - & - & - & 0.65 & 0.51 & 0.60 & 0.64 & 0.68 & 0.61 & 0.51 \\
\hline MASC & - & - & - & - & - & - & - & 0.51 & 0.55 & 0.60 & 0.73 & 0.49 & 0.49 \\
\hline MOEH & - & - & - & - & - & - & - & - & 0.42 & 0.54 & 0.45 & 0.45 & 0.50 \\
\hline MWIL & - & - & - & - & - & - & - & - & - & 0.44 & 0.59 & 0.59 & 0.39 \\
\hline PUBL & - & - & - & - & - & - & - & - & - & - & 0.83 & 0.44 & 0.57 \\
\hline PUKF & - & - & - & - & - & - & - & - & - & - & - & 0.58 & 0.55 \\
\hline TROU & - & - & - & - & - & - & - & - & - & - & - & - & 0.50 \\
\hline WARA & - & - & - & - & - & - & - & - & - & - & - & - & - \\
\hline
\end{tabular}

but this is a measure of the internal quality of the sub-sample, not bias. To assess sub-sample bias, a sub-chronology for the previously identified highquality period (A.D. 1840-1920) was built from the sub-sample of series for which data was available at A.D. 1550. The kauri master chronology was then correlated against this sub-chronology for A.D. 1840-1920. The correlation squared $\left(r^{2}\right.$, the proportion of common variance) of 0.462 , indicates that this particular subset of trees explains $46 \%$ of the variance. This is assumed to be indicative of the quality of the kauri master chronology at A.D. 1550.

The analysis described above for A.D. 1550 was repeated at 50 year intervals and at selected times where a marked change occurred in the composition of sites used to construct the master chronology (circles in Figure 8B). There is no threshold $\mathrm{r}^{2}$ value below which the kauri master should be considered useless; merely ever expanding error bars associated with any environmental reconstruction as $\mathrm{r}^{2}$ declines. However, it is readily apparent from Figure $8 \mathrm{~B}$ that there is a rapid transition from what can reasonably be judged a highquality series $\left(r^{2}>0.8\right)$ at A.D. 1600 to a much poorer series only 50 years earlier.

\section{INTER-SITE COMPARISONS}

The pervasive regional forcing identified above does not preclude significant (and potentially valuable) secondary regional-scale patterns.
These were investigated by analysing the 13 site cross-correlation matrix for the period A.D. 18401920 (Table 2), supplemented by additional PCA analyses.

Inter-site correlations range from 0.28 (TROU-KATI) to 0.83 (PUBL-PUKF), although both extreme values are anomalous because 76 of the 78 cross-correlation pairs are within the more restricted $0.35-0.73$ range. The mean correlation for each site across all other sites ranges from 0.49 (MOEH) to 0.62 (PUKF), with no clear outliers. This result differs from that reported by Buckley et al. (2000), where MOEH was identified as anomalous. The change is a consequence of the recent reanalysis of MOEH (Table 1; Boswijk and Palmer 2001).

Detailed analyses of the spatial structure of correlations were undertaken for each site (not shown). All cases revealed a complex structure and no clear spatial patterns emerged. Correlations with nearby sites tend to be relatively high, but are not necessarily the highest. Lowest correlations tend to be associated with more distant sites, but some distant sites do not have low correlations. In a few cases, the highest correlations are with relatively distant sites (cf. Ahmed and Ogden 1985).

HUIA, LTBR and PUKF are noteworthy in having normal-high ${ }^{1}$ cross-correlations with all

'For the purpose of this discussion "normal" is defined as correlations between the 25 th and 75 th percentiles $(\mathrm{R}=0.493$ $0.627)$, with "high" and "low" correlations outside those bounds. 


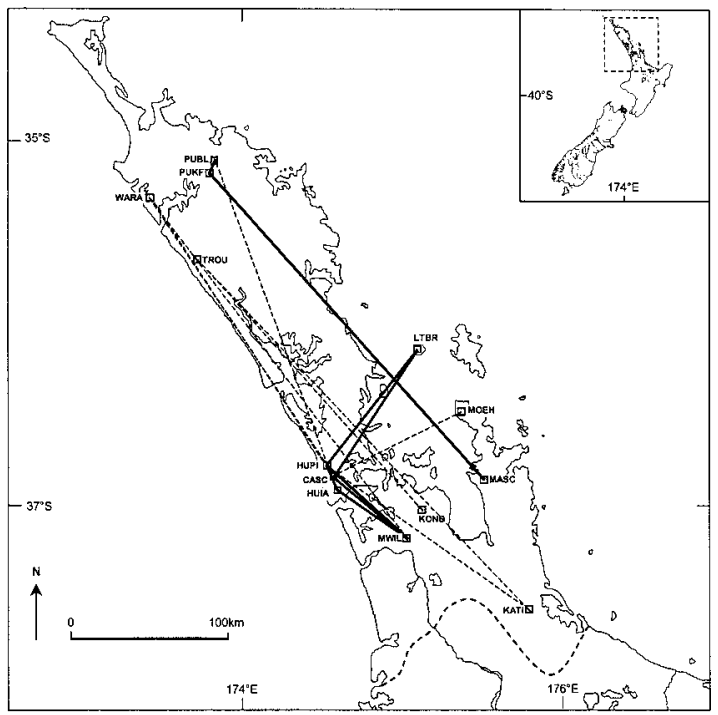

Figure 9. Highest and lowest inter-site correlations (A.D. 1840-1920). Solid lines link site pairs with the highest $10 \%$ of correlations. Dashed lines link the lowest $10 \%$ of correlations. KAWH and WAID are excluded.

sites, or all but one site. MOEH, TROU, and WARA stand out with low-normal correlations with all other sites, with MOEH the worst performer. HUPI is unusual in having three high and three low correlations. PUBL and PUKF are strongly correlated with each other, but both correlate more highly with distant southern sites than with the relatively close west coast sites (TROU, WARA). CASC, HUIA, and HUPI have a broadly similar spatial cross-correlation pattern. Correlations between themselves and with LTBR and MWIL are high whereas all other correlations are low-normal (CASC-PUKF excepted).

The suggestion of a central cluster of sites with a common signal is confirmed by Figure 9, which simplifies the cross-correlation results by showing only the high and low correlations. This highlights the consistently strong links within a cluster of four southwest sites (CASC, HUIA, HUPI, MWIL), plus an apparent link to LTBR. We hypothesise that the LTBR link relates to its exposed island position, perhaps making the environment more like that of the west coast of the mainland than that of the east coast. The other three sites linked by high correlations (MASC,

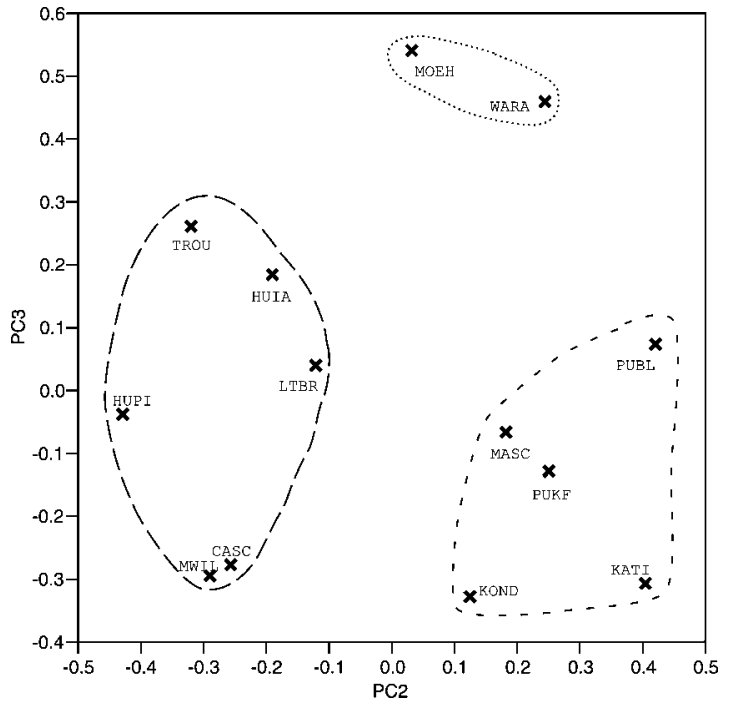

Figure 10. Site loadings on the second and third principal components. Three possible clusters are grouped.

PUBL, PUKF) suggest a possible eastern cluster (LTBR excepted).

The low correlations in Figure 9 are dominated by multiple links involving four sites (HUPI, KATI, TROU, WARA). HUPI is centrally located and its three low correlations are with three of the four northern sites. Given that HUPI is within a tentative central cluster, this may be indicative of a north-central split. Secondly, the fact that three of the eight low correlations are between the west coast sites of TROU and WARA and other west coast sites further south, leads us to conclude that a coherent west coast response is absent.

As previously noted, the key result of the PCA analysis is the dominance of the first principal component (PC1), explaining 59\% of the variance in the data. The second and third PCs account for a further $15 \%$ of the data variance $(\mathrm{PC} 2=9 \%, \mathrm{PC} 3=7 \%)$. Plotting site weighting on PC2 against weightings on PC3 (Figure 10) reveals three possible site groupings:

\section{1) CASC, HUIA, HUPI, LTBR, MWIL, TROU \\ 2) KATI, KOND, MASC, PUBL, PUKF \\ 3) MOEH, WARA}

The first group of six centrally located sites is broadly consistent with the spatial correlation pattern identified above (TROU excepted). These 
sites all have negative weightings on PC2 and are the only sites that do. Given that PC2 represents the largest amount of variance, after the common variance explained by PC1, it seems likely that this central group is the most important data subset potentially carrying a useful regionally specific signal. TROU is clearly the weakest member of the cluster. The second group has five spatially scattered "east coast" sites (KATI, KOND, MASC, PUBL, PUKF), but other east coast sites (LTBR, $\mathrm{MOEH}$ ) are not included. All have positive weightings on PC2 and weak or negative weightings on PC3. They are separated from the six site central cluster by $\mathrm{PC} 2$ and from MOEH and WARA by PC3. It may be significant that MOEH and WARA are the two highest altitude sites $(450+\mathrm{m})$.

Oblique principal component cluster analysis (SAS 1990) gave similar results to the interpretation of the PCA results reported above. For the commonly used criterion of a single eigenvalue greater than one in each cluster, only two clusters were identified: 1) the six site central cluster and 2) all other sites. Allowing the clustering to proceed further, by relaxing the criterion, resulted in the second cluster being split with MOEH and WARA again forming a separate cluster. At the next step TROU is split from the first cluster.

We conclude that there is some evidence of subtle differences in response across sites. At this stage we think only one subset of the data warrants further pursuit, namely the five site central cluster of CASC, HUIA, HUPI, LTBR, and MWIL. Dropping TROU from the cluster is a response to sometimes tenuous links to the other five sites.

\section{DISCUSSION AND CONCLUSIONS}

A common standardisation procedure was adopted for all series, based on maximising intrasite correlation amongst series. For kauri, this involved standardising with a relatively flexible smoothing spline $(50 \%$ of variance passed at 20 years). "Stripping" of lower quality series was then undertaken based on the EPS statistic of Briffa and Jones (1990), in effect removing series that weakened the common signal. The fact that, in most cases, few series were removed implies that crossdating does operate as effective implicit quality control in kauri. The stripping analyses for kauri suggest that high-quality site chronologies can usually be derived from as few as 10 trees, although more material is usually required for crossdating purposes and for replication of early parts of the chronology. Note though that this result is specific to the standardisation applied.

Graphical and statistical analysis of the 13 best site chronologies for selected high-quality time periods revealed a strong common signal across all sites. This justifies development of master chronologies for paleoclimate applications. Adopting $\mathrm{r}^{2}>0.8$ in Figure $8 \mathrm{~B}$ as an arbitrary high-quality threshold, indicates that high-quality master chronologies can be derived with confidence for A.D. 1597-1996. An implication of the latter date is that climate-tree-ring transfer functions should not include data after the A.D. 19961997 growth ring.

Comparison of the master chronology developed here with that of Buckley et al. (2000) confirms the importance of sample depth. Although calculated using different standardisation methods, the two chronologies are in good agreement from A.D. $1701-1996\left(\mathrm{r}^{2}=0.77\right)$. However, there is only very weak agreement for A.D. 1580-1700 $\left(\mathrm{r}^{2}\right.$ $=0.15)$, reflecting the very low sample depth in the Buckley et al. master. We conclude that the Buckley et al. (2000) kauri master should not be used before A.D. 1701 and recommend that it be replaced in total by a new master calculated from the expanded data set now available.

The analysis of the evolving quality of the kauri master provided some useful insights into kauri sampling strategy. First, an order of magnitude increase in sample depth results in a roughly linear increase in chronology quality. Second, achieving an $\mathrm{r}^{2}>0.8$ quality standard for a master chronology requires on the order of 25 trees from seven sites. This is a particularly interesting result, suggesting that a relatively small number of trees from multiple sites may be more valuable, in terms of deriving a master chronology, than a few highquality sites, derived from numerous trees.

Kauri master quality results also clearly indicate that future sampling needs to be directed at improving sample depth before A.D. 1597. Given 
the difficulties of obtaining material from living trees this far back in time, focus needs to turn to archival material (e.g. in museums) and relic stumps and fallen trees where bulk samples can be obtained.

Secondary patterns amongst sites are minor (relative to the common signal), subtle, and not necessarily spatial in character. Although a central cluster of sites is apparent, the generally complex nature of spatial relationships suggests that there may be other non-spatial factors that need to be resolved before significant progress is likely to be made in teasing out subtle paleoclimate information. For example, it is plausible that strong (weak) relationships over long (short) distances may be related to factors such as site characteristics or cohort age structures. Notwithstanding some potential for progress in this regard, it warrants emphasis that the significance of the common signal across kauri tree-ring sites and the lack of clear spatial patterns of secondary response demonstrates that kauri growth variation is primarily a response to regional-scale climate forcing, operating over several degrees of latitude and longitude.

Over 20 years of incremental chronology development by several researchers has resulted in a modern data base of 15 crossdated sites, 13 of which are considered high quality. Although further development will enhance this data base in space and time (the latter being the current priority) the data currently available are suitable for paleoclimate applications, especially in the form of master chronologies built from material from all sites. The kauri master presented here is ideal for quality control purposes, for dating, and is appropriate for a few high resolution paleoclimate applications. More conservative standardisation would be required for decadal- to century-scale applications.

Research currently in progress will refine relationships between growth and climate, establishing transfer functions that will be applied to midto late-Holocene long chronologies derived from kauri sub-fossil and archival material. With currently known sites, we are hopeful that continuous kauri master chronologies for the last 4,000 years will soon be derivable. Equally important, an ad- ditional high-quality data base from a data-sparse region is now available for Late-Holocene multiproxy climate change studies.

\section{ACKNOWLEDGMENTS}

Financial support for this research was provided by the New Zealand Foundation for Research, Science and Technology (FRST contract UOAX0011). Our thanks to Dr J. Palmer and Dr L. Xiong for the unpublished WAID data and to two anonymous referees for considered comment that improved the quality of the manuscript.

\section{REFERENCES CITED}

Ahmed, M., and J. Ogden

1985 Modern New Zealand tree-ring chronologies 3. Agathis australis (Salib.)_kauri. Tree-Ring Bulletin 45:11-24.

Ahmed, M., and J. Ogden

1987 Population dynamics of the emergent conifer Agathis australis (D. Don) Lindl. (kauri) in New Zealand: I. Population structures and tree growth rates in mature stands. New Zealand Journal of Botany 25:217-229.

Bell, V., and R. Bell

1958 Dendrochronological studies in New Zealand trees. Tree-Ring Bulletin 22:7-11.

Boswijk, G.

2001 Tree-ring analysis of kauri (Agathis australis) from Huia, Waitakere Ranges, Auckland New Zealand Tree-Ring Site Report No. 5. University of Auckland, Department of Geography Working Paper No. 14.

Boswijk, G., A. Fowler, and M. Bridge

2001 Tree-ring analysis of kauri (Agathis australis) from Furniss Road, Waikato. New Zealand Tree-Ring Site Report No. 7. University of Auckland, Department of Geography Working Paper No. 15.

Boswijk, G., A. Fowler, and J. Ogden

2000 Tree-ring analysis of kauri (Agathis australis) from Manaia Sanctuary, Coromandel Peninsula. New Zealand Tree-Ring Site Report No. 1. University of Auckland, Department of Geography Working Paper No. 9.

Boswijk, G., and J. Palmer

2001 Tree-ring analysis of kauri (Agathis australis) from Mt Moehau, Coromandel Peninsula. New Zealand Tree-Ring Site Report No. 3. University of Auckland, Department of Geography Working Paper No. 11.

Briffa, K., and P. Jones

1990 Basic chronology statistics and assessment. In Methods of Dendrochronology: Applications in the Environmental Sciences, edited by E. R. Cook and L. A. Kariukstis, pp. 137-152. Kluwer Academic, Dordrecht. 
Buckley, B., J. Ogden, J. Palmer, J. Salinger, and A. Fowler

2000 Dendroclimatic interpretation of tree-rings in Agathis australis (kauri) 1. Climate correlation functions and master chronology. Journal of the Royal Society of New Zealand 30:263-275.

Cook, E. R.

1985 A Time Series Analysis Approach to Tree-ring Standardization. Ph.D. dissertation, University of Arizona, Tucson, USA.

Dunwiddie, $\mathrm{P}$.

1979 Dendrochronological studies of indigenous New Zealand trees. New Zealand Journal of Botany 17:251266.

Fowler, A.

1984 A Dendroclimatological Study of Kauri (Agathis australis). Unpublished MA thesis, University of Auckland, Auckland, New Zealand.

Fowler, A., and G. Boswijk

2000 Tree-ring analysis of kauri (Agathis australis) from Cascades Kauri Park, Waitakere Ranges, Auckland. New Zealand Tree-Ring Site Report No. 2. University of Auckland, Department of Geography Working Paper No. 10

Fowler, A., and G. Boswijk

2001 Tree-ring analysis of kauri (Agathis australis) from Huapai Scientific Reserve, Huapai, Auckland. New Zealand Tree-Ring Site Report No. 6. University of Auckland, Department of Geography Working Paper No. 13.
Fowler, A., and G. Boswijk

2003 Chronology stripping as a tool for enhancing the statistical quality of tree-ring chronologies. Tree-Ring Research. 59(2):53-62.

Fowler, A., G. Boswijk, and M. Bridge

2001 Tree-ring analysis of kauri (Agathis australis) from Pukekapia, Waikato. New Zealand Tree-Ring Site Report No. 8. University of Auckland, Department of Geography Working Paper No. 16.

Holmes, R. L., R. K. Adams, and H. C. Fritts

1986 Users manual for Program Arstan. In Tree-Ring Chronologies of Western North America: California, Eastern Oregon and Northern Great Basin, pp. 5060. Laboratory of Tree-Ring Research, University of Arizona, Tucson.

La Marche, V.C., R. L. Holmes, P. W. Dunwiddie, and L. G. Drew

1979 Tree-Ring Chronologies of the Southern Hemisphere: 3. New Zealand. Laboratory of Tree-Ring Research, University of Arizona, Tucson.

Ogden, J.

1978 On the dendrochronological potential of Australian trees. Australian Journal of Ecology 3:339-356.

Palmer, J.

1982 A Dendrochronological Study of Kauri (Agathis australis). M.S. thesis, University of Auckland, Auckland, New Zealand.

SAS

1990 SAS Procedures Guide, Version 6. SAS Institute, Cary, North Carolina, USA.

Received 10 March 2003; accepted 26 September 2003. 